\title{
Virtual Rheumatology During COVID-19: A Personal Perspective
}

\author{
Jane Dacre
}

Received: June 26, 2020 / Published online: July 28, 2020

(C) The Author(s) 2020

Keywords: COVID-19; Rheumatology outpatient clinics; Virtual

\section{Key Summary Points}

Conventional face-to-face rheumatology clinics have not been possible during the COVID-19 pandemic.

This submission provides a personal view of experience of telephone clinic consultations during COVID-19.

Telephone and other virtual clinics are feasible in rheumatology and well-liked by most, but not all patients.

Although the pandemic forced this change, it is worth considering greater use of virtual working in rheumatology in the planning of post COVID-19 services.

Formal service evaluation and improvement science is now needed.

Digital Features To view digital features for this article go to: https://doi.org/10.6084/m9.figshare.12657380.

J. Dacre $(\bowtie)$

UCL Medical School, London, UK

e-mail: j.dacre@ucl.ac.uk
Many of us have been using the telephone to contact our patients for some time. About 2 years ago, I made a decision to explore the wider role of telephone clinics in rheumatology. From a personal perspective, it allowed me to contribute to my local rheumatology department, where I had worked for several years, whilst on sabbatical as President of the Royal College of Physicians (RCP). It gave me much more flexibility on the timing and location of the clinics, and was easier to fit in with a demanding schedule at the College, but allowed me to maintain personal contact with my patients. I didn't know how well it would be received, so I evaluated what I was doing to check. The evaluation was informative, and surprisingly positive. Running clinics by phone was feasible, efficient, and acceptable to most, but not all patients.

Suddenly, we were hit hard by Covid-19. During the peak of the outbreak, all of my medical colleagues except for one were redeployed to Covid wards to support the crisis. The physios were sent to help in ITU, the nurses were providing a remote intravenous service at a local private hospital. Some colleagues also became ill, or needed to self-isolate. Over a couple of weeks, there were no rheumatology clinicians to see the patients face to face, and the clinics were closed for safety reasons. I am sure this situation was repeated in several units. 
What had started as a low-key project, which was ticking over, became the preferred way of doing things. Telephone consultations were supplemented by virtual consultations, where patients' notes and results were reviewed in absentia to provide an update for the patient and GP, and to keep people safely away from the department, unless they really needed an appointment. Provision was also made for online face-to-face contact. We are all now encouraged to work from home if possible, so, with the support of the Trust Information Technology (IT) department, within a week, I was suddenly running a significant outpatient service from home.

People are now talking about never returning to the old way of doing things, and we are thinking through what the so-called 'new normal' looks like. Although this change was not planned, there are benefits to being forced to think differently about the way we run our services. Whilst president of the RCP, one of the main concerns for members was the shortage of doctors. We are running a service that is 'underdoctored, under-funded, and over-stretched', we said. More patients are living longer, with multiple co-morbidities. In rheumatology, we can now do so much more for our patients, with the advent of biologic therapies. We have some more capacity, much more work to do, and are seeing many more patients, so we need to become more efficient. There is also an argument that we are beginning to over-diagnose, over-investigate, and over-treat our patients. Some think we are over-medicalizing patients, and disempowering them. Realistically, this situation cannot continue. These same problems and debates exist for physicians and rheumatologists, and others who specialize in long-term chronic conditions all over the world.

Covid-19 has forced us to change. There has been a reduction in the number of face-to-face clinics, an increase in remote working, a stronger focus on keeping patients safe from infection, and a recognition that the current model of outpatient clinics needs to change.

In a letter to NHS Trusts during the crisis, Simon Stevens, chief executive officer (CEO) of the UK National Health Service (NHS) wrote in a letter that "all NHS secondary care providers have access to video consultation technology; video or telephone appointments should be offered by default for all outpatient activity without a procedure"...and we should "use remote appointments as a default to triage the elective backlog." We should also be thinking of implementing a "patient initiated follow-up service'. Changing outpatients was actually already part of the recent NHS Long Term Plan. The RCP and the British Society of Rheumatology (BSR) Clinical Affairs Committee have written guidance on how best to do this.

Well, OK then, why not?

The benefits of remote working include: flexibility in time and place for the patient and practitioner; reduced travel burden, with a resulting increase in environmental sustainability (5\% of the UK's road travel comes from the NHS according to a report on outpatients from the RCP), reduced costs to the NHS, and more scope for part time and flexible workers, so helpful to those with other commitments.

Challenges include not being able to examine the patient; communication difficulties, especially with language, or patients with cognitive impairment. Remote consultations do not work for everyone.

What do patients think about all this?

I asked two of my patients about it in my telephone clinic this week, and this was the response, published anonymously and unattributed with their verbal consent, to ensure ethics compliance:

"It is better in some ways. It is stressful getting into the clinic if you are coming from work; the stress of finding a parking place, then getting back to work afterwards uses up a lot of energy. With a telephone appointment, I can slip into a meeting room unnoticed. That's the best thing. I know if I need to be seen and examined, and can ask for it"

Another said "its fine, I don't mind at all. Its only worth attending if I need examining."

In my experience, those patients who struggle with a remote appointment are easily triaged to a face-to-face contact.

In the future, a key element of the postCovid redesign of rheumatology services will be better utilization of available technology. The 
NHS is now providing specific support and guidance for this. Change is often difficult, but the investment in a virtual addition to a rheumatology service is worth thinking about. No one likes change, but we cannot keep doing what we did before, as it was not working well enough, and was not efficient enough for the brave new post-Covid world.

\section{ACKNOWLEDGEMENTS}

Funding. No funding or sponsorship was received for this study or publication of this article.

Authorship. All named authors meet the International Committee of Medical Journal Editors (ICMJE) criteria for authorship for this article, take responsibility for the integrity of the work as a whole, and have given their approval for this version to be published.

Disclosures. Jane Dacre has nothing to disclose.

Compliance with Ethics Guidelines. All publication. Patient quotes are published anonymously and unattributed with their verbal consent.

Peer Review. Please note, contrary to the journal's standard single-blind peer review process, as a commentary this article underwent review by a member of the journal's Editorial Board.

Open Access. This article is licensed under a Creative Commons Attribution-NonCommercial 4.0 International License, which permits any non-commercial use, sharing, adaptation, distribution and reproduction in any medium or format, as long as you give appropriate credit to the original author(s) and the source, provide a link to the Creative Commons licence, and indicate if changes were made. The images or other third party material in this article are included in the article's Creative Commons licence, unless indicated otherwise in a credit line to the material. If material is not included in the article's Creative Commons licence and your intended use is not permitted by statutory regulation or exceeds the permitted use, you will need to obtain permission directly from the copyright holder. To view a copy of this licence, visit http://creativecommons.org/licenses/by$\mathrm{nc} / 4.0 /$. 